\title{
Managing the Invisible Hand of Expectations
}

\author{
Barry L. Wisdom \\ Missouri State University
}

All managers develop unique expectations regarding the performance and development of each of their subordinates. Because little conscious and structured attention is often paid to these expectations, their impact may be capricious at best. This article examines the power of these expectations, their origins, and the dynamics of their influence as drivers of outcomes. Managers are also offered a framework for use in the examination of these expectations with an eye toward making them more accurate, appropriate, and effective.

\section{INTRODUCTION}

Assume for a moment that you are the parent of multiple children. If someone were to ask you which child you loved the most, this question might be off putting for several reasons. In your desire to be the "good parent," you would probably cling to the belief that you love all of your children equally. That is, after all, what society might suggest is the most appropriate and desirable behavior. That position also is desirable as a means to prevent any trouble that might arise between your children over jealousies or insecurities stemming from inconsistent treatment. If this were your true feeling, then it should be reflected in the consistency with which your children are treated and in the expectations for success that you might hold for each of them. Were you the true egalitarian you would spend equal amounts of time, invest equal amounts of resources, and look for an equal number of opportunities for them to demonstrate their potential for success, or receive constructive criticism, coaching, or praise.

In the cold hard light of day, is this what most of us as parents truly do? If given total absolution, most of us would admit to having different feelings toward these children. Some we might favor because of their dispositions. Some might win our positive regard because of their adoration of us and their desire to please, build, and maintain close relationships with us. Still others might find disfavor because of their poor choices, outlandish behaviors, or lack of motivation. The bottom line is, like no two snowflakes are exactly alike, neither are the relationships we have with those around us be they children, friends or relations, colleagues, or employees. These relationships are in part defined by the expectations we construct for each individual and the dynamics involved in the maintenance of these expectations. There are several theories as to how these expectations effect outcomes and a knowledge of these theories and their implications for management practice makes them well worth the manager's time and consideration.

\section{ORIGINS OF THE DYNAMIC}

The processes by which expectations guide our behaviors are subtle, operate at the limits of our consciousness, and may seem almost magical as we are often unaware of their impact. To borrow and 
modify a phrase from the economist Adam Smith who described the subtle effect of competition on economic markets as the "Invisible hand of competition," one could refer to the dynamics relevant to this discussion as the "Invisible hand of expectations." The origins of this dynamic have ties to another dynamic that dates back to the middle of the last century where it was coined the self-fulfilling prophecy. In simple terms, this describes the holding of a belief that was initially false but when acted upon over time in a way consistent with it being true, the behavior encourages the belief to become true. For example, during the early days of the great depression in the late 1920's, when word of the stock market crash reached main streets all over the country, people believed that the banks were no longer sound. This belief was not true initially, but when people acted on this belief collectively and begin to withdraw all their deposits, the banks were unable to meet all these demands with their reserves and thus quickly became insolvent. People collectively acted on a false belief having the impact of making the belief become a reality. They created a truth based on their actions that was consistent with an initially inaccurate assumption.

In one of the earliest and best-known tests of this premise, elementary school teachers were told by researchers that after testing at the beginning of the school year, some of their students were identified and disclosed to the teachers as being intellectual bloomers expected to make above average gains by the end of the academic year. Upon testing at the end of the school year, it was determined that those students who were identified as bloomers had actually bloomed by making greater academic gains than had their peers. The interesting thing was that the bloomers were chosen totally at random with their selection and identification as bloomers having nothing to do with their pretest scores.

Why had they bloomed? It happened in large part as a result of the teachers treating the students as the bloomers they expected them to be. Anticipating positive academic outcomes, the teachers had spent more time with, given more individual attention to, reinforced more successes and corrected more failures for these students than they did for the other students not labeled as bloomers. They were not instructed to do this by the researchers, however, they were acting in a way that was consistent with the production of this outcome. So subtle was the process that at some point during the school year it is likely that the teachers would have forgotten the origins of their expectations and might have defended the position that they were treating all their students the same. In the years following this study, the self-fulfilling prophesy was found alive in additional studies on the battlefield, in welding classes, and numerous other settings. Is there any reason why these dynamics should not also be a part of the management processes in contemporary organizations?

\section{THE ORIGINS OF MANAGERIAL EXPECTATIONS}

When managers are appointed in organizations, the process typically involves either the promotion of someone from within, or the appointment or hiring of someone from outside the organization. This distinction certainly plays a role in the formation of expectations, as one moving up from within is likely to have more information about, and experience with, newly coined subordinates because they have some work history with these people. Managers coming in from outside start with a cleaner slate and are initially more dependent on second hand information that might be received from their new superiors, fellow supervisors, trainers, or gleaned from personnel files, performance records, or job applications. Regardless of origin, primary and secondary data are collected and serve as important inputs to the formation of unique expectations for each employee under the manager's supervision.

Not all managers will assign equal weights to the different types of information collected. The relative importance of this information to a large degree reflects the values of the manager. If looks are highly valued by the manager, then the subordinates with the best appearance, clothing, posture, or grooming might be identified as high potential candidates. It would also follow for this manager that those whose appearances are less than desirable might receive lower expectations for future outcomes. If verbal dexterity is prized, then candidates who speak well on their feet, use descriptive and well-chosen language, or make effective presentations might find preference while those less glib might be ticketed to a different place. 
Beyond the dimensions of sight and sound, other qualifiers/disqualifiers might deal with values, common interests, backgrounds, or a large host of factors deeply rooted in the personality of the manager. In addition, biases reflected in attitudes toward race, sex, religion, political affiliations, or age should be considered as well. To be unaware of the presence of these biases within each of us is to effectively deed a large portion of our decision-making processes to forces over which we exert minimal control. It might be somewhat like betting a poker hand without looking at your cards. This is not a practice that comes highly recommended. Instead, does it not make more sense to consciously assess and address the subtleties surrounding the formation of our expectations? The following sections give some structure and guidance to this pursuit that can lead to valuable insights for both new as well as seasoned managers.

\section{WHAT WERE YOU THINKING?}

As presented here, the above heading presents a serious, not rhetorical question for managers to ask themselves when it comes to the expectations that they hold for each of their employees. Only through some honest and careful consideration will the dynamics of expectations come to light and the invisible hand at work be revealed. All managers should start with these basic questions.

\section{What Expectations Do You Hold for Each of Your Employees?}

I would direct practicing managers to make a list of all their employees and write down the expectations they hold for each subordinate focused on the elements of the job that are most valued and relevant. For example, where are they headed with regard to quality, quantity, leadership, teamwork, commitment, development potential, initiative, etc.? Do these expectations change when consideration is given for just the next year versus five years out?

\section{On What Do You Base Your Expectations?}

Now go back over the list and think about the origins of the information that led to the formation of these expectations. Did it come from personal observations, performance data, secondhand reports, experience, or somewhere else? Is it possible that your expectations have been colored by your personal biases or prejudices, or have they been potentially distorted in any way by inaccurate data? Do you feel that your expectations are solid, reasonable, or shaky? Is there enough evidence to make them hold up in court?

\section{Are Your Expectations For Your Subordinates Desirable?}

In writing the end of the storyline you have scripted for each of your workers, do you see a good ending or a bad one? If it is a bad ending, can you see circumstances where the script might be rewritten to produce a different and more desirable outcome? As you are examining these expectations remember that not every employee can be the star and not every employee is the dog. As people vary on both sides of the mean, so do the expectations you might construct for your workers. You do not want to be over critical or too lenient as you try to view your workers; you are simply trying to be as objective as possible.

\section{WHAT ARE THEY THINKING?}

Perhaps the next step in the process is to find out the goals, aspirations, and expectations held by each of your subordinates. It is standard practice during an interview to ask a potential employee what they plan to be doing, or where they might see themselves, a few years down the road. Our interest in the answer to these questions should not evaporate when the hiring decision is made. The practice of helping employees articulate their visions could be, and perhaps should be, incorporated into the regular performance evaluation process. This would provide GPS coordinates as to future expectations.

\section{Do Their Expectations Align with Your Own?}

Do your expectations align with your employees or do they present a totally different picture from the one you have painted? Do the inconsistencies, if there are any, come from the manager, the employee, or 
possibly from inaccurate information? How could these divergent patterns of expectations be reconciled? Can they be? Does a redirection of expectations need to occur and if so, does the primary responsibility for that redirection rest on you the manager, or on the employee, or perhaps on both?

\section{HOW DO WE GET ON THE SAME PAGE?}

After a manager has carefully gone through the processes prescribed previously, now is the time to consider follow up actions to put things on the proper course. The value of the insights you have acquired through the preceding steps can now be invested in human futures with an increased probability of positive payoff.

\section{Full Speed Ahead}

If your analysis points to a healthy and accurate set of common expectations being held by you and your subordinates, then the future is clear. You may proceed with a renewed confidence that you and your employees are moving in the appropriate direction. This feeling should be enhanced by the fact that you have now examined and discussed expectations with your subordinates and confirmed reasonable and appropriate paths for the future.

\section{Can You Get There from Here?}

If your subordinates' expectations are at odds with your own, then action plans need to be proposed. If the issue is one of their expectations being inflated relative to their observed talents, then a frank discussion about skill development and more realistic targets for attainment might refocus their efforts. In order to summon a suggested route for a proposed trip from any travel software or phone application, there need to be two concrete data points available for input. These reflect where you are going and where you are now. You cannot get there if you do not know both. An accurate grounding in the present is therefore a piece of information vital to the process. If the employee is unaware of deficiencies in their skill set, than they may lack the equipment necessary for the trip, regardless of where they may wish to go.

\section{Aim a Little Higher?}

If your expectations are higher than your subordinates' then the issue may be one of low self-efficacy or motivation on their part. Perhaps the employee is unaware of a natural gift or has not bothered to look very far into the future in consideration of what his or her potential might be. This presents an opportunity to encourage an employee to expand horizons and consider some outcomes he or she may have never before considered. It is an opportunity to invite the employee to dream larger than he or she would have ever dreamt alone. To have someone profess his or her faith in your ability to realize a desirable but previously unconsidered future can be an incredibly gratifying and motivating gift. Some people just do not dream large enough.

\section{A TASK WORTH DOING}

A manager's day is often so filled by a multitude of demands that few of us are in the habit of looking for more tasks to do. The time required to do the analysis of expectations suggested in this work is minimal, but in the long run could have a large positive pay back well worth the time and effort required. Imagine a workforce where all the employees have an accurate understanding of their abilities and skills. Imagine all employees having a unique, appropriate, and confirmed vision of their role and future within the organization. Finally, envision a supervisor who can effectively serve as a committed guide for each employee along the way to his or her charted destination. If these visions were brought to life, it would surely be to the betterment of the employees, the managers, and their organizations. Look at this as a way to challenge the status quo and unleash the power of expectations for the benefit of everyone. 